\title{
МЕТОДОЛОГИЯ ОЦЕНКИ ПРОЦЕССОВ ЦИФРОВОЙ ТРАНСФОРМАЦИИ В ЭКОНОМИЧЕСКИХ СИСТЕМАХ
}

\author{
(C) 2019 Гулый Илья Михайлович \\ кандидат экономических наук, доцент \\ Петербургский государственный университет путей сообщения \\ Императора Александра I, Россия, Санкт-Петербург \\ E-mail: ilya.guliy@mail.ru
}

На современном этапе развития российской экономики традиционная модель экономического роста за счет инвестирования в основной капитал или финансовых инвестиций утрачивает свое прежнее значение. Статистические тренды последних лет подтверждают факт формирования в национальной экономике начального этапа цифровой модели развития. Экономическая наука должна углублять, дополнять существующие и предлагать новые положения, методологии, закономерности, с опорой на которые субъекты экономики смогу планировать, оценивать, организовывать свою дальнейшую деятельность в направлении цифровой трансформации.

В статье проводится обоснование методологии оценки протекающих процессов цифровизации в деятельности организаций, отраслевых комплексов, в частности, в развитии транспортной системы как важнейшей инфраструктурной основы национальной экономики. На базе изучения статистических показателей в сфере цифровизации формируются выводы относительно уровня и динамики происходящих процессов цифровой трансформации в экономических системах. Предложенная методология будет способствовать получению объективной оценки о процессах цифровизации в различных сферах экономической деятельности, конкретизации системы планирования в рамках построения в стране цифровой экономической модели.

Ключевые слова: инвестиции в циифровые технологии; цифровая модель экономики; статистика процессов цифровизации.

На современном этапе развития российской экономики происходит смещение акцента развития с опоры на традиционную модель, основанную на росте реальных инвестиций (инвестиции в основной капитал) на новую основу - цифровую [2]. Статистические тренды и закономерности это подтверждают. В последние годы темы роста цифровых инвестиций существенно опережают рост реальных инвестиций (рис. 1). Уровень инвестиций в основной капитал в 2018 г. по российской экономике ниже уровня 2012 г., в то время как вектор цифровых инвестиций устойчиво повышательный, особенно за последние 3 года $[1,3]$.

Для оценки уровня и динамики процессов цифровой трансформации необходимы актуальные методики, позволяющие экономическим субъектам понимать свои позиции в цифровом мире, формировать программы, проекты, стратегии [5] перехода к цифровой трансформации.

Предлагаемая в статье методология основана на использовании официального статистического материала, публикуемого Росстатом по итогам получения сведений от крупных и средних организаций по форме 3-Информ «Сведения об использовании информационных и коммуникационных технологий и производстве вычислительной техники, программного обеспечения и оказании услуг в этих сферах» [6]. В указанном информационном источнике содержится ценная информация, позволяющая оценивать и анализировать состояние и динамику цифровых процессов в организациях по видам деятельности.

Автором выбраны важнейшие показатели, содержащиеся в статистике Росстата по цифровым технологиям (в разрезе видов деятельности и регионов):

- затраты организаций на информационно-коммуникационные технологии;

- численность специалистов по информационно-коммуникационным технологиям;

- количество организаций, использовавших системы электронного документооборота;

- число организаций, использовавших «облачные сервисы»; 


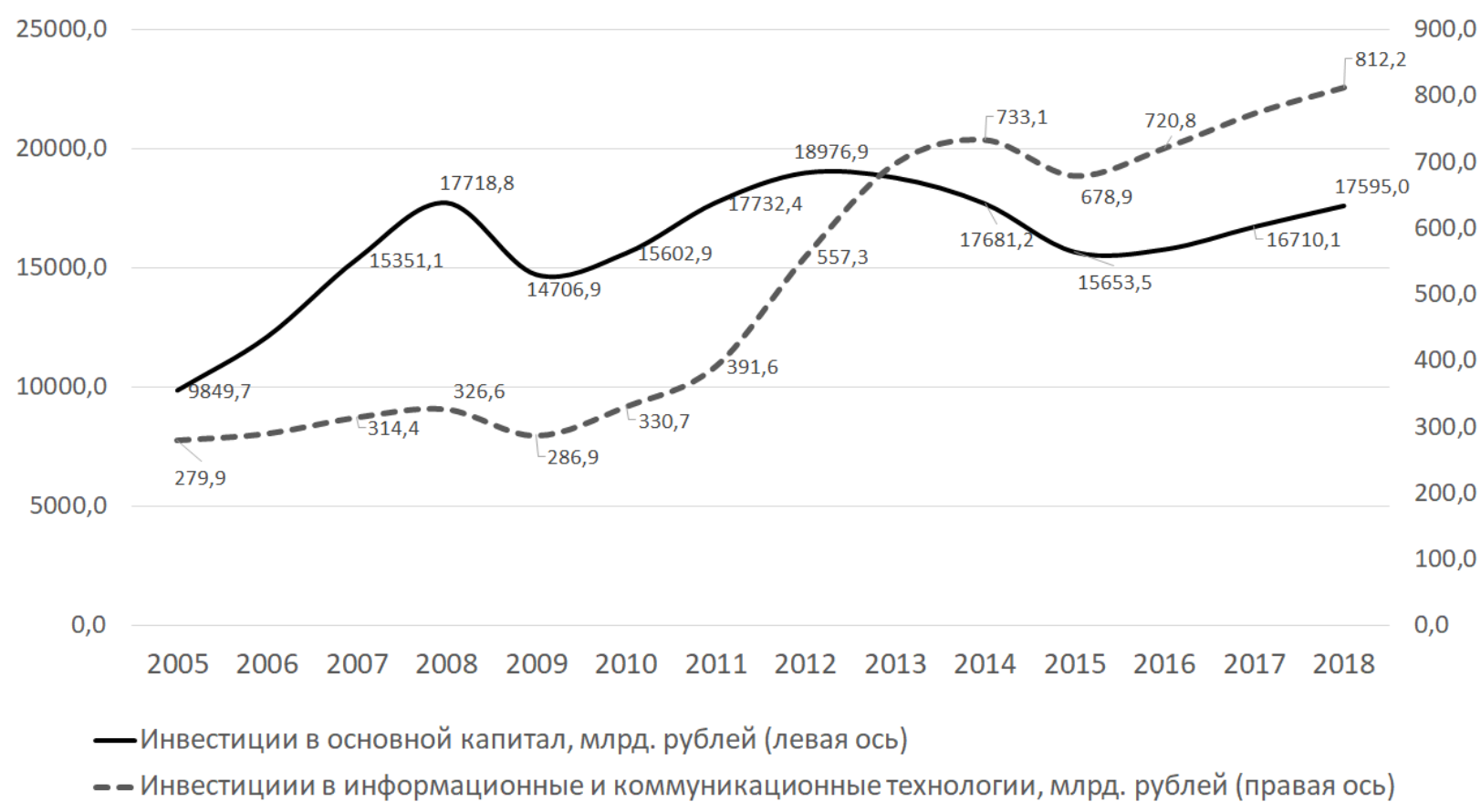

Puc. 1. Динамика инвестиций в основной капитал и инвестиций в информационные и коммуникационные (цифровые) технологии, в целом по экономике России, за период с 2005 г. по 2018 г., в сопоставимых ценах 2018 г., млрд. рублей

Источник: построено автором на основе [8].

Примечание: показатели инвестиций в действующих ценах приведены в сопоставимый вид на основе официальных статистических индексов инфляции.

В методологии Росстата к инвестициям в информационные и коммуникационные (цифровые) технологии относятся затраты на приобретение вычислительной техники, телекоммуникационного оборудования, программного обеспечения.

• число организаций, применявших SCM, CRM, ERP - системы;

- число организаций, использовавших программные средства для управления закупками и продажами;

- число организаций, использовавших программы для управления автоматизированным производством и/или отдельными техническими средствами и технологическими процессами;

- количество организаций, использовавших технологии автоматической идентификации объектов (RFID), позволяющие посредством радиосигналов считывать или записывать данные;

- число организаций, использовавших геоинформационные и навигационные системы;

- количество организаций, использовавших системы сбора, хранения, обработки, анализа, моделирования и визуализации массивов данных;

- количество организаций, использовавших средства обеспечения облачных и распределен- ных вычислений, средства виртуализации и системы хранения;

- количество организаций, использовавших информационные системы управления проектами, исследованиями, разработкой, проектированием и внедрением.

Данные позволяют оценить инвестиционную составляющую цифровизации, а также масштабы и динамику распространения таких технологий, как «Большие данные - BigData», «Распределенные реестры - блокчейн», «Интернет вещей - IоT», «Электронные сервисы взаимодействия с поставщиками и потребителями» и других [7].

Предлагаемые автором показатели, которые необходимо рассчитать на основе статистической базы, приведены на рис. 2.

Рассчитываемые показали различны по своему содержанию: доля организаций, доля персонала, доля в обороте и др. Поэтому для оценки уровня развития цифровых процессов по видам деятельности необходимо показатели перевести 


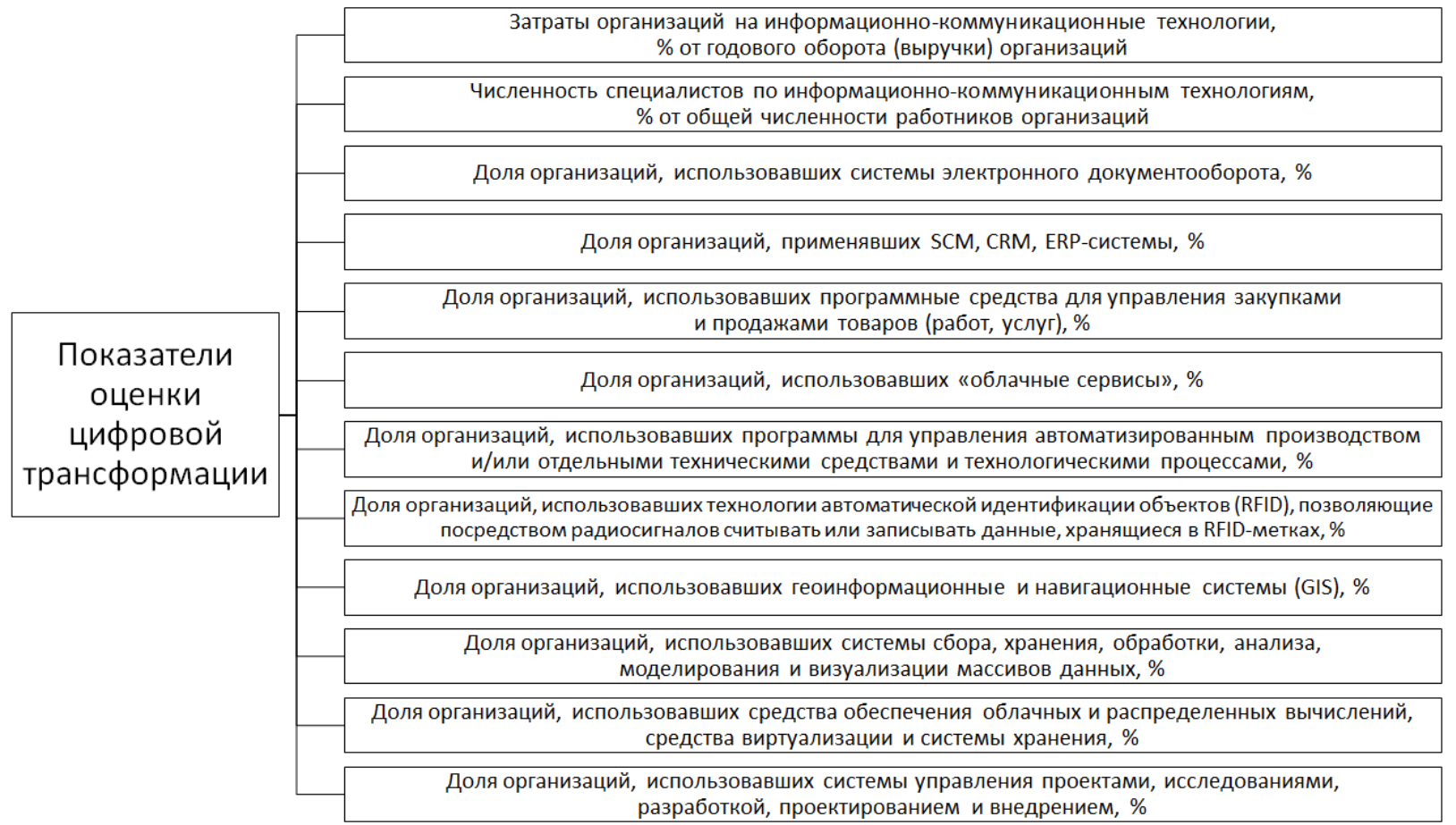

Puc. 2. Предлагаемые показатели оценки цифровой трансформации на уровне видов деятельности, отраслей, отраслевых комплексов Источник: авторская разработка.

в сопоставимый вид в доли единицы (формула):

(Значение показателя - Минимальное значение среди показателей по обследуемым видам деятельности) / (Максимальное значение показателей по обследуемым видам деятельности - Минимальное значение показателей по обследуемым видам деятельности) (1)

Рассчитанные показатели позволят локально определить развитие отдельных процессов цифровизации. Предлагаемая градация уровней: 0,81-1,00: высокий; 0,61-0,80: выше среднего; 0,41-0,60: средний; 0,21-0,40: ниже среднего; 0-0,20: низкий.

Усреднив значения всех предложенных 12 показателей - коэффициентов, получим обобщающий показатель текущего состояния развития процессов цифровизации по видам деятельности.

Рассмотрим отдельные показатели цифровизации по отраслям экономики. На рис. 3-10 приведены рассчитанные показатели по российским крупным и средним организациям в разрезе видов деятельности за период с 2016 по 2018 гг.

На примере транспортного комплекса мож- но провести его характеристику с точки зрения современного состояния происходящих изменений в сфере внедрения цифровых технологий. На транспорте наиболее активно и интенсивно происходят процессы: цифрового инвестирования, внедрения программ для управления автоматизированными техпроцессами (косвенно характеризующих внедрение технологий Интернета вещей). Вместе с тем, российский транспорт как отраслевой комплекс существенно отстает от других видов деятельности по доле специалистов по ИТ-технологиям, внедрению современных SCM, CRM, ERP-систем, облачных сервисов, систем сбора, хранения, обработки, анализа, моделирования и визуализации массивов данных (по определению - это технологии BigData), систем обеспечения облачных и распределенных вычислений, средств виртуализации и системы хранения (технологии блокчейн).

По предложенной выше формуле 1 рассчитаем значения показателей развития цифровых процессов и технологий для транспортного комплекса (табл. 1). По полученным данным видны «узкие» места и сдерживающие сегменты по внедрению «цифры» (ряд проблем обозначен выше). 


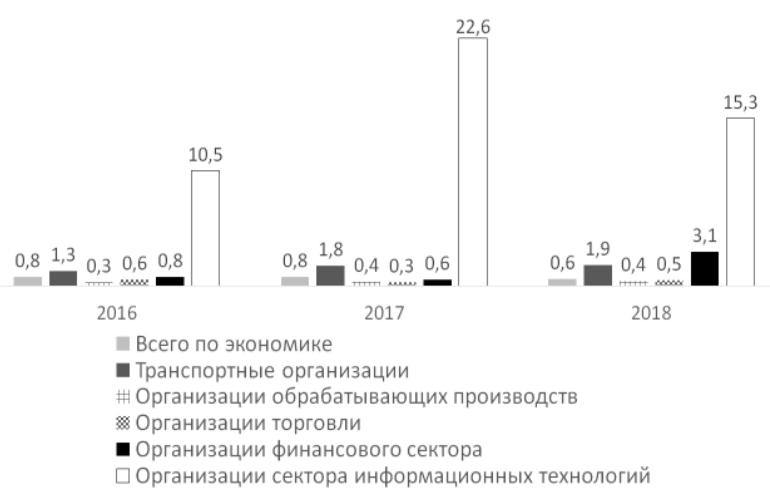

Puc. 3. Динамика затрат организаций на информационно-коммуникационные технологии, \% от годового оборота (выручки) организаций
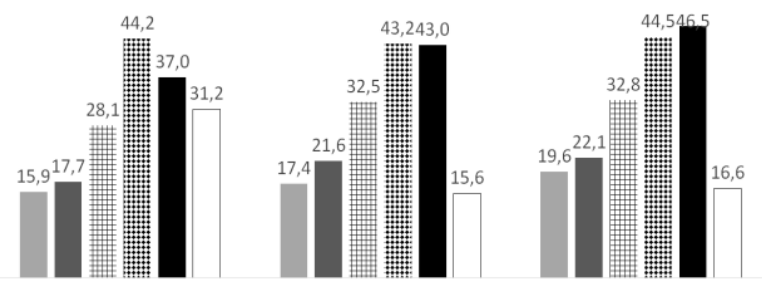

2016

2017

всего по экономике

орые организащии

\# Организации обрабатывающих производств

\#: Организации торговли

- Организации финансового сектора

$\square$ Организации сектора информационных технологий

Рис. 5. Доля организаций, применявших SCM, CRM, ERP-системы, \%

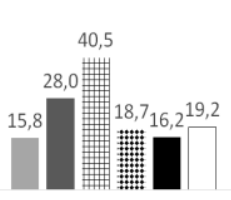

2016

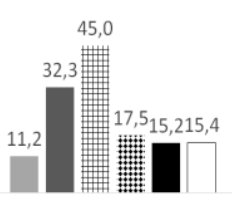

2017

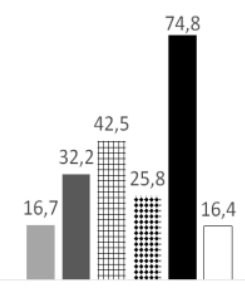

2018
Всего по экономике

- Транспортные организации

\# Организации обрабатывающих производств

:: Организации торговли

- Организации финансового сектора

$\square$ Организации сектора информационных технологий

Рuc. 7. Доля организаций, использовавших программы для управления автоматизированным производством и/или отдельными техпроцессами, \%

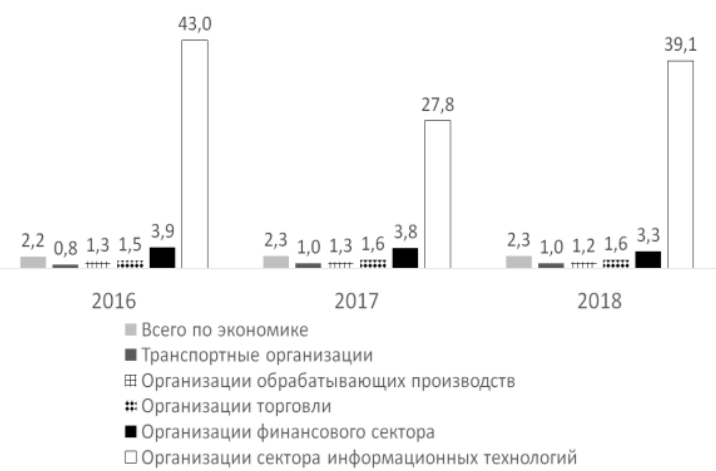

Puc. 4. Динамка доли специалистов по информационно-коммуникационным технологиям, \% в общей численности работников организаций

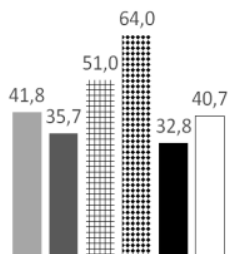

2016

- Всего по экономике

- Транспортные организации

\# Организации обрабатывающих производств :: Организации торговли

- Организации финансового сектора

๑ Организации сектора информационных технологий

Puc. 6. Доля организаций, использовавших программные средства для управления закупками и продажами, \%

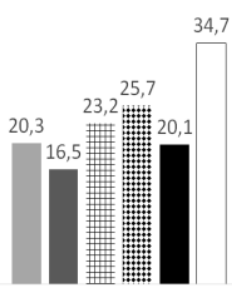

2016

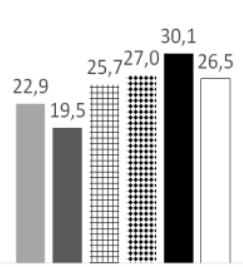

2017

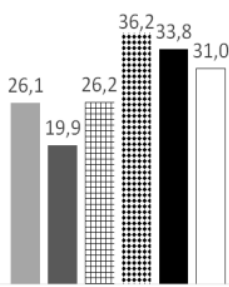

2018 всего по экономике

- Транспортные организации

\# Организации обрабатывающих производств

:: Организации торговли

— Организации финансового сектора

$\square$ Организации сектора информационных технологий

Puc. 8. Доля организаций, использовавших «облачные сервисы», \% 


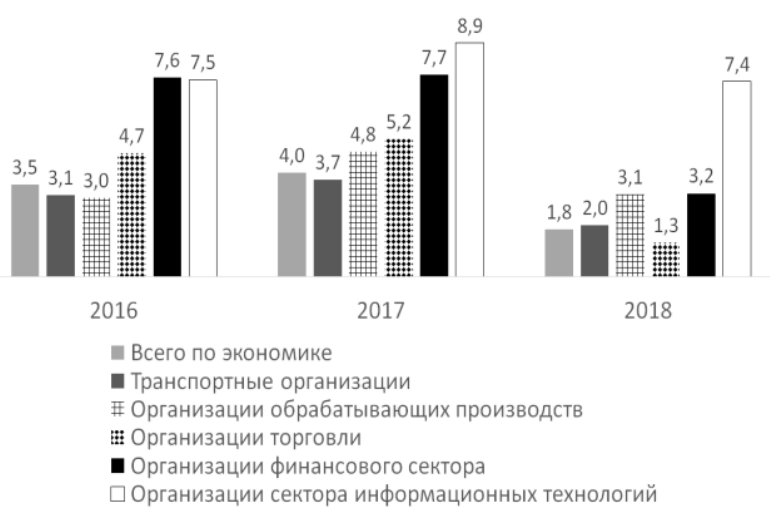

Рис. 9. Доля организаций, использовавших

системы сбора, хранения, обработки, анализа, моделирования и визуализации массивов данных, \%
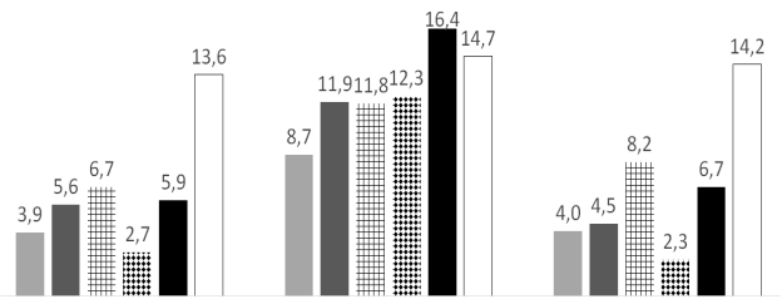

2016

2017

2018

Всего по экономике

- Транспортные организации

\# Организации обрабатывающих производств

:: Организации торговли

- Организации финансового сектора

$\square$ Организации сектора информационных технологий

Puc. 10. Доля организаций, использовавших средства обеспечения облачных и распределенных вычислений, средства виртуализации и системы хранения, \%

Источник: рассчитано автором на основе $[4,6]$.

Таблица 1. Расчетные значения показателей уровня развития цифровых процессов и технологий в целом по транспортному комплексу России в 2016-2018 гг. (в долях единицы)

\begin{tabular}{|c|c|c|c|}
\hline Показатели & 2016 & 2017 & 2018 \\
\hline Затраты организаций на информационно-коммуникационные технологии & 0,101 & 0,067 & 0,099 \\
\hline Численность ИТ-специалистов & 0,002 & 0 & 0,007 \\
\hline Число организаций, применявших SCM, CRM, ERP-системы & 0,099 & 0,279 & 0,244 \\
\hline $\begin{array}{l}\text { Число организаций, использовавших программные средства для управления } \\
\text { закупками и продажами }\end{array}$ & 0,092 & 0,279 & 0,127 \\
\hline Число организаций, использовавших системы электронного документооборота & 0 & 0,334 & 0,357 \\
\hline $\begin{array}{l}\text { Число организаций, использовавших программы для управления автоматизиро- } \\
\text { ванным производством и/или отдельными техническими средствами и техноло- } \\
\text { гическими процессами }\end{array}$ & 0,495 & 0,626 & 0,288 \\
\hline $\begin{array}{l}\text { Число организаций, использовавших технологии автоматической идентифика- } \\
\text { ции объектов (RFID) }\end{array}$ & 0,380 & 0 & 0,364 \\
\hline Число организаций, использовавших «облачные сервисы» & 0 & 0,000 & 0 \\
\hline $\begin{array}{l}\text { Число организаций, использовавших геоинформационные и навигационные } \\
\text { системы }\end{array}$ & 0,606 & 1,000 & 1,000 \\
\hline $\begin{array}{l}\text { Число организаций, использовавших системы сбора, хранения, обработки, } \\
\text { анализа, моделирования и визуализации массивов данных }\end{array}$ & 0,366 & 0,358 & 0,227 \\
\hline $\begin{array}{l}\text { Число организаций, использовавших средства обеспечения облачных } \\
\text { и распределенных вычислений, средства виртуализации и системы хранения }\end{array}$ & 0,266 & 0,420 & 0,183 \\
\hline $\begin{array}{l}\text { Число организаций, использовавших системы управления проектами, } \\
\text { исследованиями, разработкой, проектированием и внедрением }\end{array}$ & 0,000 & 0,391 & 0,203 \\
\hline Обобщающий показатель & 0,230 & 0,405 & 0,299 \\
\hline
\end{tabular}

Источник: рассчитано автором на основе [4, 6]. 
Обобщающий показатель развития процессов цифровизации для транспортного комплекса на современном этапе находится на уровне «ниже среднего», по многим обозначенным выше причинам.

Предложенный автором подход возможно применять при экономическом обосновании проектов, программ, стратегий цифровизации на уровне отраслей, комплексов, групп компа- ний, объединений. Конкретизация показателей развития цифровых процессов сможет более точно определять ключевые показатели эффективности (KРI) для отраслевых органов государственной власти, проектных менеджеров, участников межведомственных проектов внедрения цифровых технологий в различных отраслях российской экономики.

\section{Библиографический список}

1. Zhuravleva N. Mathematical description and modelling of transportation of cargoes on the base digital railway / Zhuravleva N., Guliy I., Polyanichko M.// Vide. Tehnologija. Resursi: XII starptautiskas zinatniski praktiskas konferences materiali 2019.gada 20-22 junijs. Lsejums. Rezeknes Tehnologiju, 2019. - 263 lpp.

2. Гулый И.М. Транспортно-логистические системы в цифровой экономике: монография / И.М. Гулый.- Вологда: ФГБУН ВолНЦ РАН, 2018. - 201 с.

3. Журавлева Н.А. Проблемы оценки цифровых технологий на транспорте / Журавлева Н.А. // Транспорт Российской Федерации. 2019. - № 3 (82). - С. 19-22.

4. Индикаторы цифровой экономики: 2019: стат. сб. / Г.И. Абдрахманова, К.О. Вишневский, Л.М. Гохберг и др.; Нац. исслед. ун-т «Высшая школа экономики».- М.: НИУ ВШЭ, 2019.- 248 с.

5. Об утверждении программы «Цифровая экономика Российской Федерации»: распоряжение Правительства РФ от 28 июля 2017 г. № 1632-р [Электронный ресурс].- Режим доступа: http://www.government.gov.ru.Дата обращения: 01.11.2019.

6. Официальная статистическая отчетность крупных и средних организаций по форме 3-Информ «Сведения об использовании информационных и коммуникационных технологий и производстве вычислительной техники, программного обеспечения и оказании услуг в этих сферах» / Федеральная служба государственной статистики (Росстат) [Электронный ресурс].- Режим доступа: http://www.gks.ru.- Дата обращения: 15.11.2019.

7. Паспорт национального проекта «Цифровая экономика Российской Федерации» [Электронный ресурс].Режим доступа: https://digital.gov.ru. - Дата обращения: 10.11.2019.

8. Российский статистический ежегодник. 2018: стат. сб. / Росстат.-М., 2018._694c. 